\title{
The Daunting Challenge of Ensuring Sustainable Development of Nanomaterials
}

\author{
Mónica J. B. Amorim \\ Department of Biology \& CESAM, University of Aveiro, Aveiro 3810-193, Portugal; mjamorim@ua.pt; \\ Tel.: +351-234-247-093 \\ Academic Editor: Paul B. Tchounwou \\ Received: 16 February 2016; Accepted: 18 February 2016; Published: 22 February 2016
}

\section{Introduction}

The development and implementation of nanomaterials (NMs) is rapid and a vast range of applications is already in place or foreseen. Consequently, there is a concomitant increased likelihood for NMs being released into the environment. Given this, there is concern regarding the potential ecological sustainability of nanotechnology [1]. Although, this concern has driven an impressive progress in the field of nanotoxicology, there is a considerable need for data that can support fate, exposure and hazard assessment and the modelling thereof.

This Special Issue aimed to tackle the aforementioned requirements by providing a focus on the exposure and effects of NMs in biological systems and the related risk assessment in the environment and for humans. This includes results from novel material and exposure characterisation within various media and biological models; over effect assessment ranging from standard biological endpoints at the population level to subcellular levels, including mechanistic-based studies, to aspects of modelling, risk characterisation, intelligent testing strategies, and safer-by-design approaches.

\section{Challenges and Prospects}

Two decades since the start of NMs Environmental Health and Safety (EHS) studies (e.g., [2]), research has evolved rapidly but challenges persist [3]. The current paradigm of NMs is that the materials characteristics and properties are posing different challenges from those of the traditional chemicals, and also specific requirements in their risk evaluation. In line with this NMs have been given particular attention in terms of regulation and funds [4] in various regions, e.g., in EU [5,6] and in the US [7], by OECD (Organization for Economic Co-operation and Development) WPMN (Working Party on Manufactured Nano-materials).

Despite the increased focus and progress of NM-related EHS research, several challenges remains for which there are no current solutions, take, for instance, the current lack of proper quantification methods and technology for NMs in test media. Detection and quantification becomes even more difficult when in complex matrixes [8], not to mention that detection limits are often not sufficiently low for detecting materials in environments. The establishment of the required information regarding characterization of NMs has been discussed [9]. This has certain advantages e.g. to account for the possibility of comparability between studies, preferably under standardized procedures (OECD, ISO (International Standard Organization)), and the possibility of future developments and a posteriori data completion.

A fundamental issue in NMs EHS research is the narrowness of available tools, e.g., the most up-to-date existing quantitative technologies, which still only make basic characterization, are available in very few labs worldwide, making it inaccessible for the majority of researchers and referential laboratories. However, focus should be on quantifying the NM relevant and specific biological effects measured (e.g., [10]), regardless of the current impossibility to fully quantify the NMs in media, 
as long as studies detail the experimental design sufficiently and are carried under standardized procedures or GLP (Good Laboratory Practices). Despite these challenges, inspiring potential lays in high-throughput techniques, such as omics or multi-endpoints systems, where the possibility to understand the mechanisms of action and build up information towards a systems toxicology approach is highlighted [11]. This high-throughput data may also be used for the basis for grouping and read-across approaches [12], approaches which are needed as it is not possible to test each and all NMs in a detailed and timely manner, nor efficient and desired. Coupled with this fast data, longer term exposures to PECs (Predicted Environmental Concentrations) [13] should be carried out, as it may be required to assess effects of NMs and worse case scenarios, longer than the required and established for traditional chemicals. Such new test methods or improvements and adaptations to the existing ones can be very valuable tools in the current framework, e.g., full life cycle tests [14] where additional endpoints and information can be retained and help to discriminate nano effects from non-nano.

Hence, despite the benefits offered by standard methods, efforts should be invested in novel techniques and endpoints, giving the necessary room to explore and the chance to discover the key issues that involve the fate and effect of NMs. As far as to the risk estimations, the most beneficial approach is a flexible and more inclusive approach for NMs Risk Assessment [15]. An intelligent testing strategy (ITS) for NMs is preferred [16].

Acknowledgments: Supported by the European Commission, funding FP7-SUN: SUstainable Nanotechnologies (Ref. 604305).

Conflicts of Interest: The author declares no conflict of interest.

\section{References}

1. Stone, V.; Pozzi-Mucelli, S.; Tran, L.; Aschberger, K.; Sabella, S.; Vogel, U.B.; Poland, C.; Balharry, D.; Fernandes, T.; Gottardo, S.; et al. Research Prioritization, to Deliver an Intelligent Testing Strategy for the Human and Environmental Safety of NM; ITS Nano Consortium: Edinburgh, UK, 2013.

2. Oberdörster, G.; Ferin, J.L.B. Correlation between particle-size, in vivo particle persistence, and lung injury. Environ. Health Perspect. 1994, 102, 173-179. [CrossRef] [PubMed]

3. Roco, M.C.; Mirkin, C.A.; Hersam, M.C. Nanotechnology research directions for societal needs in 2020: Summary of international study. J. Nanoparticle Res. 2011, 13, 897-919. [CrossRef]

4. European Parliament (EP). European Parliament Resolution of 24 April 2009 on Regulatory Aspects of Nanomaterials; EP: Strasbourg, France, 2009; pp. 1-10.

5. ECHA (European Chemicals Agency). Regulations: Nanomaterials. Available online: http:/ /echa.europa.eu/ regulations/nanomaterials (accessed on 16 February 2016).

6. Savolainen, K.; Backman, U.; Brouwer, D.; Fadeel, B.; Fernandes, T.; Kuhlbusch, T.; Landsiedel, R.; Lynch, I.; Pylkkänen, L. Nanosafety in Europe 2015-2025: Towards Safe and Sustainable Nanomaterials and Nanotechnology Innovations Nanosafety in Europe Towards Safe and Sustainable Nanomaterials and Nanotechnology Innovations; Finnish Institute of Occupational Health: Turku, Finland, 2015.

7. National Science and Technology Council Committee on Technology (CoT). National Nanotechnology Initiative: Environmental, Health, and Safety Research Strategy; CoT: Washington, DC, USA, 2011.

8. Navratilova, J.; Praetorius, A.; Gondikas, A.; Fabienke, W.; von der Kammer, F.; Hofmann, T. Detection of engineered copper nanoparticles in soil using single particle ICP-MS. Int. J. Environ. Res. Public Health 2015, 12, 15756-15768. [CrossRef] [PubMed]

9. OECD (Organisation for Economic Cooperation and Development). Guidance on Sample Preparation And Dosimetry For The Safety Testing Of Manufactured Nanomaterials Series on the Safety of Manufactured Nanomaterials No. 36. Available online: http:/ /www.oecd.org/officialdocuments/publicdisplaydocumentpdf/ ?cote $=\mathrm{env} / \mathrm{jm} / \mathrm{mono} \% 282012 \% 2940 \&$ doclanguage $=$ en (accessed on 16 February 2016).

10. Ribeiro, M.; Maria, V.; Scott-Fordsmand, J.; Amorim, M. Oxidative Stress Mechanisms Caused by Ag Nanoparticles (NM300K) are Different from Those of $\mathrm{AgNO}_{3}$ : Effects in the Soil Invertebrate Enchytraeus crypticus. Int. J. Environ. Res. Public Health 2015, 12, 9589-9602. [CrossRef] [PubMed]

11. Amorim, M.J.B.; Roca, C.P.; Scott-Fordsmand, J.J. Effect assessment of engineered nanoparticles in solid media-Current insight and the way forward. Environ. Pollut. 2016, 11. [CrossRef] [PubMed] 
12. Oomen, A.G.; Bleeker, E.A.J.; Bos, P.M.J.; van Broekhuizen, F.; Gottardo, S.; Groenewold, M.; Hristozov, D.; Hund-Rinke, K.; Irfan, M.A.; Marcomini, A.; et al. Grouping and read-across approaches for risk assessment of nanomaterials. Int. J. Environ. Res. Public Health 2015, 12, 13415-13434. [CrossRef] [PubMed]

13. Gottschalk, F.; Lassen, C.; Kjoelholt, J.; Christensen, F.; Nowack, B. Modeling flows and concentrations of nine engineered nanomaterials in the Danish environment. Int. J. Environ. Res. Public Health 2015, 12, 5581-5602. [CrossRef] [PubMed]

14. Bicho, R.C.; Santos, F.C.F.; Gonçalves, M.F.M.; Soares, A.M.V.M.; Amorim, M.J.B. Enchytraeid Reproduction TestPLUS: Hatching, growth and full life cycle test-An optional multi-endpoint test with Enchytraeus crypticus. Ecotoxicology 2015, 3, 1053-1063. [CrossRef] [PubMed]

15. Bos, P.M.J.; Gottardo, S.; Scott-Fordsm, J.J.; van Tongeren, M.; Semenzin, E.; Fernandes, T.F.; Hristozov, D.; Hund-Rinke, K.; Hunt, N.; Irfan, M.A.; et al. The MARINA risk assessment strategy: A flexible strategy for efficient information collection and risk assessment of nanomaterials. Int. J. Environ. Res. Public Health 2015, 12, 15007-15021. [CrossRef] [PubMed]

16. Scott-Fordsmand, J.J.; Pozzi-Mucelli, S.; Tran, L.; Aschberger, K.; Sabella, S.; Vogel, U.; Poland, C.; Balharry, D.; Fernandes, T.; Gottardo, S.; et al. A unified framework for nanosafety is needed. Nano Today 2014, 9, 546-549. [CrossRef]

(C) 2016 by the author; licensee MDPI, Basel, Switzerland. This article is an open access article distributed under the terms and conditions of the Creative Commons by Attribution (CC-BY) license (http://creativecommons.org/licenses/by/4.0/). 